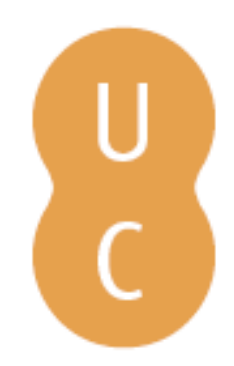

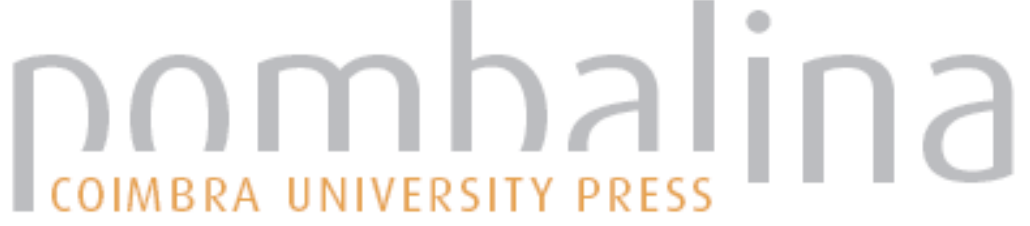

\section{Da Liga Latina ao saque de Roma}

Autor(es): $\quad$ Faversani, Fábio; Joly, Fábio D.

Publicado por: Imprensa da Universidade de Coimbra

URL

persistente: URI:http://hdl.handle.net/10316.2/36913

DOI: $\quad$ DOI:http://dx.doi.org/10.14195/978-989-26-0954-6_5.1

Accessed : $\quad$ 26-Apr-2023 13:27:19

A navegação consulta e descarregamento dos títulos inseridos nas Bibliotecas Digitais UC Digitalis, UC Pombalina e UC Impactum, pressupõem a aceitação plena e sem reservas dos Termos e Condições de Uso destas Bibliotecas Digitais, disponíveis em https://digitalis.uc.pt/pt-pt/termos.

Conforme exposto nos referidos Termos e Condições de Uso, o descarregamento de títulos de acesso restrito requer uma licença válida de autorização devendo o utilizador aceder ao(s) documento(s) a partir de um endereço de IP da instituição detentora da supramencionada licença.

Ao utilizador é apenas permitido o descarregamento para uso pessoal, pelo que o emprego do(s) título(s) descarregado(s) para outro fim, designadamente comercial, carece de autorização do respetivo autor ou editor da obra.

Na medida em que todas as obras da UC Digitalis se encontram protegidas pelo Código do Direito de Autor e Direitos Conexos e demais legislação aplicável, toda a cópia, parcial ou total, deste documento, nos casos em que é legalmente admitida, deverá conter ou fazer-se acompanhar por este aviso.

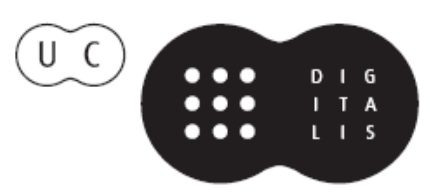


JOSÉ LUÍS BRANDÃO FRANCISCO DE OLIVEIRA (COORD.)

IMPRENSA DA

UNIVERSIDADE

DE COIMBRA

COIMBRA

UNIVERSITY

PRESS
HISTÓRIA DE
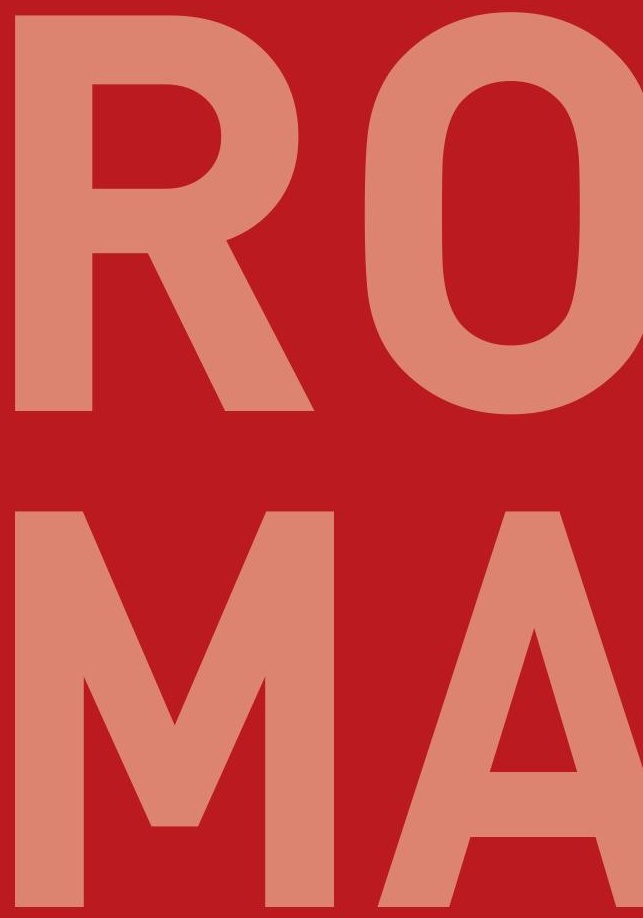

ANTIGA

VOLUME I

DAS ORIGENS À

MORTE DE CÉSAR 
5. EXPANS Ã O NA I T ÁLIA

5.1. DA Liga LATINA AO SAQUE DE ROMA

Fábio Faversani \& Fábio Duarte Joly

Universidade Federal de Ouro Preto

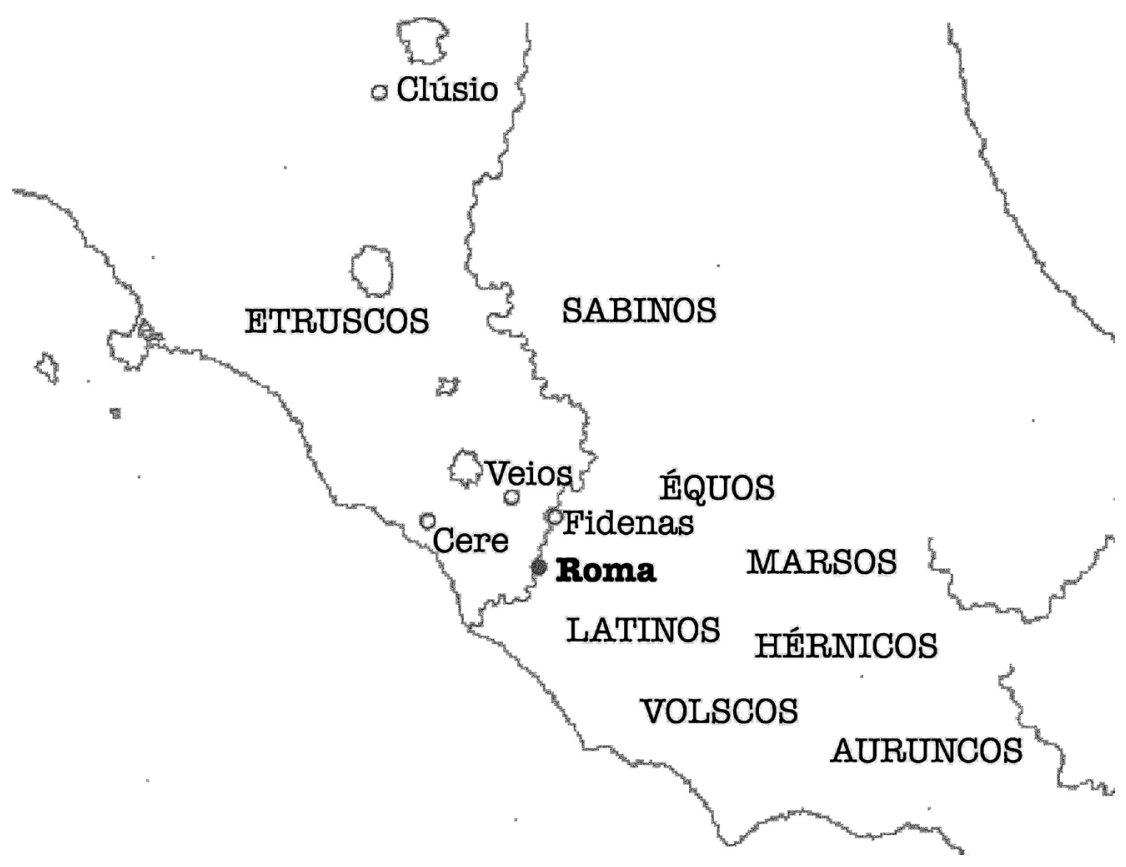

Povos da Itália central - por Fábio Mordomo 
Sumário: A Liga Latina: das origens, o tratado conhecido como foedus Cassianum e a fundação de colônias latinas. A conquista de Veios e as relações entre cidades latinas e etruscas. O saque gaulês e suas motivações. A rápida recuperação de Roma.

\section{Introdução}

O fim da Monarquia se deu com a expulsão do rei Tarquínio, apelidado de "o Soberbo". Mas o passado de dominação etrusca legou uma posição de proeminência que a aristocracia de Roma por certo não gostaria de perder junto com o poder centralizado de um rei. Deste modo, tão importante quanto construir uma saída política com uma nova forma de partilha do poder no interior da cidade - que resultou no longo processo de formação da República - foi articular um arranjo de poder para fora da cidade, particularmente com as demais comunidades políticas do Lácio.

Os primórdios da República, assim, são marcados por dois conflitos que estão ligados. Um deles, para dentro da cidade, ficou conhecido como as "lutas da plebe", de 494 a 287 a.C. Seu início é marcado exatamente por uma secessão da plebe, como visto no capítulo anterior, deixando claro o peso do elemento militar envolvido na disputa ${ }^{1}$. Este peso se deve ao fato de que o outro conflito que envolve a constituição da República Romana é a expansão do poder da cidade, e da própria cidadania, um longo processo que levou Roma a ser o Estado dominante na Península Itálica. Na medida em que novos territórios eram ligados a Roma, novas pessoas (ou mais propriamente famílias) passavam a fazer parte da cidade e de seu governo, no momento em que adquiriam a cidadania romana ou aspiravam a ela ${ }^{2}$, mesmo sendo um escravo capturado em guerra, por exemplo. Um marco neste processo são as vitórias nas duas primeiras

\footnotetext{
${ }^{1}$ Vide atrás Rodrigues cap. 4.

${ }^{2}$ Uma boa expressão dessa expansão é dada por Ênio, que, em seus Annales, escritos no século II a.C., diz com certo exagero: "Os Campanianos foram então feitos cidadãos romanos" (5.157) (Ciues Romani tunc facti sunt Campani).
} 
Guerras Púnicas (264-241 e 218-201 a.C.) que deram a Roma a hegemonia não só sobre praticamente toda a Península Itálica, mas também em vastas porções do Mediterrâneo Ocidental.

O processo de expansão, assim, dificilmente pode ser explicado como um povo, os Romanos, de ethos militarista e belicoso, irresistivelmente conquistando outros povos ${ }^{3}$. O processo de conquista, desde seus primórdios, talvez se explique melhor como um processo dirigido pelos interesses conflituosos e bastante instáveis de diversas aristocracias. Estas aristocracias, que dirigiam comunidades políticas mais ou menos autônomas, podiam se aliar a outras aristocracias ou ainda entrar em guerra com aquelas que, ainda há pouco, eram suas aliadas. Além disso, cada uma destas aristocracias tinha que manter seu poder sobre as comunidades políticas que dirigiam e ainda sobre as populações que não eram parte destas comunidades políticas, mas que estavam sob seu domínio (como os escravos e outros sujeitos sem direito à cidadania) ${ }^{4}$. Não teria existido, portanto, desde o princípio, uma centralidade inequívoca de Roma5.

Neste capítulo, analisaremos os primórdios deste processo de expansão do poderio romano, isto é, de seu imperium.

\section{A Liga Latina e o foedus Cassianum}

É neste quadro complexo de lutas entre cidades e lutas no interior das cidades que podemos entender melhor a expansão inicial de Roma. Após a expulsão de Tarquínio, o Soberbo, os patrícios têm dificuldades para impor a ordem inicialmente desenhada para a República. O descontentamento alcançava vários espaços sociais no interior da cidade

\footnotetext{
3 Como sustenta, por exemplo, o trabalho clássico de Harris 1979.

${ }^{4} \mathrm{O}$ quadro que apresentamos, portanto, é bastante diferente de uma visão mais comum em que Roma coordena um conjunto de aristocracias que vão aderindo a seu império e se beneficiam por fazer parte dele. Para esta concepção, ver, dentre outros, Crawford 1992.

${ }^{5}$ É o que, por exemplo, A. M. Eckstein designou de "anarquia multipolar" como característica do sistema interestatal mediterrâneo, no sentido de que as tendências expansionistas desse sistema exerciam pressões significativas, ao longo do tempo, tanto sobre as culturas internas quanto sobre o comportamento interestatal de Roma e de outros Estados (Eckstein 2006 3-4).
} 
e a insatisfação tocava os que eram escravizados por dívida e também os plebeus "ricos" que não podiam dirigir a cidade. Esta divisão interna enfraquecia a cidade, que se colocava em uma posição frágil frente a seus vizinhos.

A expulsão do rei Tarquínio, a nosso ver, não obedeceu a fronteiras étnicas, de uma rebelião de Romanos contra os Etruscos, como se salientou atrás ${ }^{6}$. Longe disto, a expulsão do rei não afastou os Etruscos que viviam na cidade e gozavam de grande prestígio ${ }^{7}$. Tito Lívio apresenta um grande conflito que teria ocorrido depois da queda do rei. Este teria procurado construir alianças para invadir Roma e retomar o poder. Os Romanos teriam vencido heroicamente em duas ocasiões, nas batalhas contra Porsena (507 a.C.) e especialmente em Lago Regilo (499 ou 496 a.C.) ${ }^{8}$. A ênfase de Tito Lívio recai neste confronto entre "monarquistas" e "republicanos", mas uma outra leitura destes episódios é possível. Se considerarmos, seguindo Tácito (Hist. 3.72) e Plínio, o Velho (Nat. 34.139) que os Romanos foram derrotados por Porsena 9 e aceitaram termos de paz desvantajosos, e que a batalha de Lago Regilo foi uma virada neste equilíbrio que desfavorecia Roma, a chave de leitura, então, passa a ser não um conflito étnico (Romanos $\mathrm{x}$ Etruscos) ou de formas de governo (monarquistas $\mathrm{x}$ republicanos), mas de disputa entre elites pela hegemonia do Lácio. Nesta disputa, estavam integrados, de um e de outro lado, Etruscos, Romanos e Latinos, monarquistas ou republicanos. Estas divisões que foram dadas posteriormente para explicar os conflitos de Roma em uma retrospectiva ampla, como produzida por Tito Lívio, poderiam não fazer sentido então.

\footnotetext{
${ }^{6}$ Vide Leão e Brandão, cap. 2 2.1, e Brandão, cap. 3 §.

7 Segundo Cornell (1989 262), "a presença de nomes etruscos entre os cônsules do início da República prova pontualmente que o fim da Monarquia não desenhou a expulsão como um todo dos Etruscos; o registro arqueológico mostra que a influência cultural etrusca continuou, sem ruptura, mesmo ao longo do século V".

8 Vide Brandão, cap. 2. §2.

${ }^{9}$ A versão expressa por Tito Lívio de que Porsena estivesse tentando reinstalar Tarquínio no poder é especialmente inverossímil uma vez que Tarquínio era aliado dos adversários de Porsena na região. Sendo assim, é mais provável que Porsena tenha guerreado para destituir o rei romano do que para reabilitá-lo, como nos conta Tito Lívio.
} 
É mais plausível pensar que, neste momento, para manter o poder sobre os plebeus internamente e se impor aos seus adversários fora da cidade na disputa pela hegemonia do Lácio, os patrícios romanos buscaram ampliar sua aliança com seus aliados-inimigos, ou seja, com os aristocratas latinos, com quem disputavam a hegemonia na região. Estabilizar estas lutas locais teria se mostrado fundamental para esta nova elite que emergiu com a República se consolidar no poder. Esta é a origem de um acordo que nos foi transmitido por Dionísio de Halicarnasso, um historiador de origem grega que escreveu sua obra Antiguidades Romanas em fins do século I a.C. Escrevendo cerca de quatrocentos anos depois do episódio que narra, ele diz que o foedus Cassianum (ou o acordo de Cássio), de 493 a.C., foi uma compensação dada pelos Romanos aos Latinos por eles não terem se aproveitado da primeira secessão da plebe em 494 a.C. para atacar a cidade. Pelo contrário, diz-nos Dionísio, eles estavam prontos a apoiar os governantes contra os rebeldes, se necessário. O texto do acordo como dado por nossa fonte tardia era o seguinte:

Que se tenha paz entre os Romanos e todas as cidades latinas enquanto o céu e a terra permanecerem na mesma posição; que eles nem façam a guerra um contra o outro, nem chamem inimigos de outras partes, nem deem livre passagem àqueles que façam guerra, mas que ajudem uns aos outros com todo seu poder quando atacados, que tenham uma parte igual nos espólios e butins conquistados de suas guerras conjuntas e que facilitem que os contratos privados sejam julgados com dez dias e no lugar onde os contratos foram feitos. (6.95.2)

Mesmo considerando que o registro possa estar distorcido em razão do tempo decorrido, dando um papel exagerado a Roma neste tratado de ajuda mútua e não-agressão dos primórdios da República, alguns aspetos restam claros. Em primeiro lugar, trata-se mais de um acordo de guerra do que de um acordo de paz. As cidades se aliam para, seguras que não haverá guerra entre elas, poderem estar fortes e unidas para fazer guerras e conquistar saques e butins a serem divididos entre si. É um acordo que visa estabilizar a hegemonia no campo da região e no interior 
de cada uma das cidades. Os contratos devem ser respeitados e deve ser dado apoio ativo para que as querelas se resolvam sem interferências de outras cidades que poderiam se aproveitar da estabilidade decorrente de eventuais rebeliões internas. Pelo contrário, deveriam apoiar sua repressão, como afirma Dionísio ser a própria origem do foedus Cassianum.

Deste modo, ainda que a Liga Latina existisse de algum modo por alianças entre Roma e outras cidades latinas antes do foedus Cassianum (como, aliás, indica Liv. 7.12.7) e que se consolida com ele, devemos ler criticamente nossas fontes quando elas apresentam esta aliança como sinalizando uma diferença hierárquica gigantesca, em que os aliados fornecem seus exércitos a Roma que, em troca, concede-lhes uma condição privilegiada nos processos de conquista conduzidos pelos Romanos. Estas visões das fontes posteriores estão marcadas pela realidade da relação de Roma com suas colônias latinas durante os séculos III e II a.C., de modo que isto não nos deve levar a crer em uma ligação direta entre os dois momentos e ainda menos que o significado de latino neste contexto posterior (vinculado a comunidades e pessoas que gozavam de um status diferenciado) tenha equivalência com aquele dos princípios da República, quando designaria principalmente um conjunto de comunidades com vários traços culturais e políticos em comum no Lácio ${ }^{10}$. Ademais, parece difícil aceitar que, com o foedus Cassianum, tenha se formado uma liga que unificasse de forma homogênea os Latinos (Oakley 2004 22). O mais provável é que alianças diversas, com naturezas as mais díspares os reunisse, mais do que houvesse uma única aliança largamente dominada por Roma. Tal situação é sugerida, por exemplo, por uma passagem de Festus (276L s.v. praetor), que retoma Cincius Alimentus (século III a.C.):

Os Albanos controlavam os eventos até o rei Tulo. Então, após a destruição de Alba, até o consulado de P. Decius Mus [340 a.C.] os povos

\footnotetext{
10 Tito Lívio diz que os Latinos e os Romanos: "eram similares na linguagem, costumes e, sobretudo, nas instituições militares" (Liv. 8.6.15). Mas Cornell (1995 295-7) destaca também que essa unidade de caráter mais geral não deve nos levar a crer que houvesse uma Liga Latina que reunisse de modo uniforme todas as cidades do Lácio, especialmente Roma, em uma aliança militar e política que alinhasse de forma estável as elites destas cidades.
} 
latinos estavam acostumados a deliberar em Caput Ferentinae, abaixo do Monte Alba, e a designar o comando [imperium] por comum acordo. Consequentemente, em um ano em que, por ordem da nação latina, os Romanos foram requisitados a enviar comandantes ao exército, muitos de nossos compatriotas costumavam observar os auspícios no Capitólio em direção ao sol nascente.

Em muitas ocasiões, portanto, outras comunidades, que não Roma, ficavam à frente dos exércitos. Um contexto, que, para Gary Forsythe (2005 188), provavelmente prevaleceu no século V a.C., no Lácio, diante das incursões dos Volscos e Équos. Parece importante estar atento às diferentes temporalidades imbricadas na formação da Liga Latina (Bringmann 2007 22). Há aquelas que marcam os relatos e levam para o passado elementos de uma hegemonia romana que ainda não existia, mas há também elementos de um passado mais remoto que parecem ter alguma permanência na constituição deste conjunto de alianças. Um elemento claro disto é a existência de comunidades associadas na região antes de sua urbanização, que é relativamente tardia (c. 630-580), e que pode ter facilitado tanto a existência de cultos comuns originários (como o de Iuppiter Latiaris no monte Albano, cf. Plin. Nat. 3.68-9) de um tempo em que a pecuária tinha uma predominância clara (e a fixação populacional não era tão rígida) quanto de direitos recíprocos concernentes à migração entre estas unidades políticas que vão surgindo e de casamentos e relações comerciais entre seus membros (migratio, conubium e commercium; cf. Liv. 8.14; Cic. Caec. 35). Insistimos que a constituição destas alianças provavelmente se concentrava nos extratos superiores das comunidades e não se referiam a características étnicas, mas às aristocracias que viviam na região e que tinham origem bastante diversificada (inclusive etrusca).

Ainda que a Liga Latina não tenha sido estabelecida pelo foedus Cassianum e mesmo que a Liga não representasse uma unidade clara e permanente, podemos dizer que ela foi muito ativa no período que sucede a assinatura do acordo entre Roma e as demais cidades latinas. $\mathrm{Na}$ primeira metade do século V a.C., os Latinos enfrentaram de forma articulada uma série de ameaças que os colocou praticamente em um 
estado constante de guerra. É neste quadro que se junta a esta aliança também os Hérnicos, população que conhecemos mal por não haver muitas informações sobre eles nas fontes e por não serem também muitas as informações que podemos ter acerca destas populações através da arqueologia. Eles correspondem a uma aliança de estados de origem sabina, independentes, que se uniu aos Latinos em 486.

\section{Colônias latinas}

Com as vitórias, esta Liga, reunindo Roma e estados independentes latinos e sabinos, precisou gerenciar uma multiplicidade de regimes jurídicos e formas políticas para realizar a distribuição dos espólios de guerra entre os vencedores. A apropriação das terras pelos vitoriosos engendrou a constituição de novas comunidades que eram como estados soberanos independentes, com sua própria cidadania e território (Cornell 1989 277).

Com isto, muitas colônias foram surgindo no território conquistado ou reconquistado, e estes novos estados eram associados desde o início à Liga e se obrigavam a contribuir para o esforço militar ao mesmo tempo em que gozavam de prerrogativas equivalentes aos estados membros ${ }^{11}$. Com isto, era possível não só garantir território novo aos vencedores, mas incorporar novas populações à aliança, uma vez que parte dos habitantes nativos era agregada à nova colônia por meio da concessão de cidadania e participação nos exércitos ${ }^{12}$.

Desse modo, fica claro que a constituição do imperium se pautou pela articulação de mecanismos de submissão e cooptação, em que as elites aristocráticas de diversos centros políticos, com status diferentes, estavam vinculadas através do centro de poder representado por Roma

\footnotetext{
${ }^{11}$ Uma exceção é representada por Ferentino que originalmente pertencia ao território hérnico e gerou uma nova comunidade que se vinculou à Liga Hérnica, aliada, por sua vez, aos Latinos, como vimos. (Liv. 4.51.7-8).

12 Cf. Bringmann 2007 20. Este é o caso documentado de Âncio, por exemplo. Em 467 a.C., uniram-se na nova colônia os antigos habitantes volscos, e também Romanos, Latinos e Hérnicos (Liv. 3.1.7 e D.H. 9.59.2).
} 
e sua aristocracia, que seria cada vez menos da cidade de Roma e mais uma composição de elites das diversas partes dos territórios submetidos a seu imperium.

Contudo, é importante destacar que a existência das colônias não era sempre estável. Um bom exemplo é Fidenas (D.H. 5.60.4): fundada inicialmente por Rômulo, foi restabelecida em 498 a.C. e destruída em 426. Outras perderam seu status de colônia para assumir condições jurídicas diversas da sua inicial. Isto explica porque a lista das colônias que Tito Lívio nos diz existir em 209 a.C. nos parece incompleta (Liv. 27.9). Lívio não menciona em sua lista colônias que ele mesmo narrou sua fundação em momentos prévios de seu relato. Possivelmente tais colônias mudaram de status ou simplesmente desapareceram depois de algum tempo decorrido de sua fundação. Isto nos faz ressaltar mais uma vez que a manutenção das comunidades políticas era algo exposto a inúmeras instabilidades e era crítico para isto o quadro de alianças entre as cidades, incluídas aí as colônias.

As colônias se integravam em um quadro mais amplo de cidades e aristocracias articuladas por Roma, correspondendo em especial àquelas comunidades políticas que receberam a cidadania romana (ainda que mantivessem sua organização política própria) e outras que receberam diferentes formas de cidadania que as ligavam à cidade de Roma, mas as mantinham como entidades que gozavam de alguma autonomia, como é representado pelo caso das civitates sine suffragio, que mencionaremos adiante. Pensando nesse conjunto mais amplo, Crawford (1988 21) afirma que "as relações entre Roma e qualquer comunidade italiana eram conduzidas por meio de vínculos pessoais entre os estratos superiores das duas cidades, baseadas numa íntima comunidade de interesse e envolvendo contatos frequentes, inclusive por casamentos".

\section{Guerras com Sabinos, Équos e Volscos}

Neste contexto de expansão, percebe-se um aumento da tensão no Lácio uma vez que os Volscos controlavam a parcela meridional da região. 
A área litorânea de Âncio a Tarracina, que fora controlada por Tarquínio, o Soberbo, o último rei de Roma, estava em mãos volscas. A parcela a oeste dos domínios dos aliados hérnicos, também. Movimentos populacionais ocorreram de forma mais ou menos simultânea, tendo como origem populações sabinas, que buscavam novas terras quando havia fome ou excesso de população. Um exemplo é o uer sacrum (primavera sagrada), ritual segundo o qual todos os nascidos em determinada primavera eram devotados ao deus Marte e, quando cresciam, deveriam seguir um animal selvagem e estabelecer uma nova ocupação no local em que ele parasse para repousar ${ }^{13}$. Estes movimentos, como se pode imaginar, geravam efeitos em cadeia para outras comunidades já estabelecidas na região.

Outro movimento importante se refere à ocupação da Campânia, ao sul do Lácio, pelos Samnitas. Isto levou a mudanças em algumas cidades, como no caso de Cápua, onde a aristocracia etrusca foi violentamente destituída pelos recém-chegados (Liv. 4.37.1). Estas movimentações, naturalmente, geravam novas pressões, com efeitos em cadeia uma vez mais. Mais a leste, os Équos, uma população assentada nas montanhas na direção dos Apeninos, exerciam pressão sobre as cidades localizadas nas porções mais baixas, como Tíbur, Pedo e Preneste.

Se no caso destes movimentos quem mais sofria eram as cidades nas fronteiras do Lácio, que acabavam por resguardar Roma de efeitos mais diretos, as movimentações de populações sabinas incidiam diretamente contra a principal cidade do Lácio de então. Os contatos entre estas duas populações eram intensos, como mostra a lenda do rapto das Sabinas, que se deu logo nos primórdios da história da cidade e, depois, com a presença de dois reis romanos de origem sabina (Numa Pompílio e Anco Márcio) e várias famílias importantes reclamando esta mesma origem (como os Valérios e os Póstumos). Cornell atribui a redução da atividade econômica em Roma no século V (quando comparada com a do século VI, bastante mais rica) a estes ataques constantes de populações sabinas postadas em terras mais altas contra áreas de interesse romano nas planícies e contra a própria cidade de Roma. Considerando também os

13 OLD s.v. ver sacrum; Cornell 1989 284; 1995305. 
registros de fundação de templos - que, em geral, podem ser construídos por conta da obtenção de butins de guerra - nota-se um grande intervalo de cerca de cinquenta anos entre 484 (Castor) e 433 (Apolo), quando nenhum templo é fundado. Este dado é, para Cornell (1989 287), mais um sinal de que vitórias importantes não foram obtidas pelos Romanos neste período em que a pressão demográfica sobre o Lácio, especialmente a pressão direta exercida pelos Sabinos, foi um obstáculo para a expansão de Roma.

Quando pensamos na Roma vitoriosa, militarmente imbatível, que é a imagem que a maior parte dos nossos contemporâneos tem em mente, é difícil imaginar a Roma dos tempos da República com sua autonomia seriamente ameaçada por populações com uma organização militar que não era invejável, como os Sabinos. Dois episódios, cuja historicidade efetiva é difícil de aceitar - mas que os Romanos posteriores tinham como certos - fornecem uma ideia mais concreta destes tempos difíceis vividos por Roma no século $\mathrm{V}$ e que poderia ter levado a cidade a ser dominada, ou mesmo completamente destruída, como foram tantas outras na península Itálica.

O primeiro episódio nos leva de volta à guerra conduzida pelo dissidente Coriolano (Liv. 2.33.4-40.11; D.H. 6.92-8.62) que se aliou aos Volscos e obteve uma sucessão de vitórias contra populações que estavam em seu caminho para Roma. Chegando às portas da cidade, é demovido pela sua mãe e pela sua esposa em seguir com o ataque final (que parecia a todos o levaria à vitória; nas palavras de Tito Lívio [2.40.2]: "Uma vez que as armas dos homens não puderam defender a cidade, que as preces e as lágrimas das mulheres a defendessem"). Convencido por suas parentas a não destruir sua cidade de origem, Coriolano volta para viver entre os Volscos, que o mataram. Tito Lívio deixa claro que foi graças à fortuna que este iminente perigo foi afastado. As desavenças entre as tropas aliadas que já se preparavam para um novo ataque no ano seguinte levaram a que combatessem entre si, perdendo a oportunidade de submeter Roma (D.H. 8.14-36 e Liv. 2.39-40).

O segundo episódio nos leva de volta a um personagem paradigmático para a aristocracia romana: Cincinato. Em 458 a.C., este nobre romano 
arava os campos com as próprias mãos, quando é chamado a assumir a ditadura. As tropas romanas estavam cercadas pelos Équos em Algido e bastante próximas da derrota. Cincinato, então, reúne um contingente rapidamente, marcha sobre o inimigo e o derrota. Cumprida a missão, ele renunciou a seus poderes extraordinários para voltar a seu arado (Liv. 3.26-29). Mesmo que Tito Lívio nos diga que a vitória romana foi acachapante, resultando na humilhação dos inimigos cujas vidas foram poupadas desde que eles aceitassem literalmente o jugo romano, o fato de Roma ter visto o inimigo às suas portas novamente em 457 e 455 nos faz duvidar da exatidão do relato.

Mas o ponto que nos interessa aqui, como no episódio anterior, é que restava claro para os Romanos posteriores que a manutenção da cidade de Roma se deveu a um desfecho extraordinário. Para os Romanos, estava claro que Roma poderia ser submetida e destruída a qualquer momento. Os conflitos com os vizinhos Équos, Volscos e Sabinos levaram a guerras contra diferentes coalizões de forma quase que ininterrupta ao longo século V. Praticamente não se passava um ano sem que combates em defesa dos domínios de interesse de Roma não se dessem.

A batalha do Monte Algido (431 a.C.) sinaliza uma mudança neste quadro de equilíbrio militar que não permitia a emergência de uma comunidade política na região. A importância deste combate para os Romanos fica evidente quando percebemos a permanência de elementos épicos nos relatos deste conflito pelo historiador Tito Lívio. Além disso, depois deste conflito contra Équos e Volscos, só temos notícias de guerras contra eles novamente em 423 e 413 (Volscos) e 421, 418, 414 (Équos). Os Sabinos, por sua vez, já não aparecem mais mencionados em conflitos desde meados do século V. Quer porque Roma conseguiu impor alguma soberania neste contexto, quer porque estas populações tenham se estabilizado com relação aos movimentos migratórios mais frequentes vividos antes (ou provavelmente por uma associação entre estes dois fatores), o fato é que nossas fontes passam a dar mais ênfase aos conflitos que os Romanos terão com inimigos situados mais ao norte, especialmente os Etruscos de Veios.

Cabe ressaltar que as guerras entre Romanos, Volscos, Équos e Sabinos não representaram fronteiras tão claramente marcadas, sendo os aliados 
de hoje os inimigos de amanhã. Deste modo, não se pode confundir estes conflitos com aqueles que mais tarde serão vividos por Roma entre exércitos especializados e dedicados exclusivamente à guerra, com aparatos políticos mais claramente distinguíveis (Southern 2011 59). Talvez as expressões usadas por Tito Lívio para descrever os anos de 498-495 e um ataque sabino em 495 sejam úteis para clarificar esse ponto. O primeiro caso, ainda que Tito Lívio esteja se referindo aos combates com Veios, antes do início das três guerras de que trataremos adiante, parece se enquadrar bem à situação que queremos ilustrar. Ele diz Triennio deinde nec certa pax nec bellum fuit ("No triênio seguinte não houve nem paz nem guerra certa”, 2.21.1), enquanto no segundo, afirma: tumultus enim fuit verius quam bellum ("Foi assim mais um tumulto do que verdadeira guerra", 2.26.1).

Logo, é preciso respeitar as particularidades de cada período da longa história de Roma, evitando reforçar uma ideia muito frequente de um poderio militar estável e irresistível, e que acaba por ofuscar a exata noção da posição de Roma no século $\mathrm{V}$ e as dificuldades que enfrentou para se afirmar como uma potência na área central da península Itálica.

\section{Conquista de Veios}

A cidade de Veios era a cidade etrusca mais próxima a Roma, distando cerca de quinze quilômetros. Os conflitos entre ambas vêm desde o tempo do fundador Rômulo. Mas no início da República, estes conflitos ganharam uma maior importância ${ }^{14}$. Podemos distinguir mais claramente três grandes momentos do conflito, normalmente designados como primeira guerra veia (483-474), segunda guerra veia (437-426) e terceira guerra veia (405-396). Diversamente do que ocorrera contra os Équos e Volscos, em que predominaram guerras de razia envolvendo desde confederações

14 Se é verdade, como dizíamos antes, que as pressões de Équos e Volscos recaíam mais sobre os aliados latinos, a ameaça representada por Veios incidia diretamente sobre Roma. Cf. Oakley 200423. 
de comunidades mais ou menos organizadas até famílias atuando isoladamente, entre Veios e Roma temos guerras entre dois estados, portanto, com combates mais claramente definidos ${ }^{15}$.

$\mathrm{Na}$ primeira guerra veia temos uma vantagem para os Etruscos. Eles se saem vencedores e praticamente eliminam uma das gentes romana mais importantes, a gens Fabia $^{16}$. O fim do conflito se dá em 474 com um acordo de paz que estabelece o controle etrusco sobre Fidenas, uma região fundamental para os interesses romanos, especialmente no que concerne ao controle do rio Tibre.

O início da segunda guerra veia se dá exatamente como uma tentativa romana de retomar Fidenas ${ }^{17}$. O conflito parece ter sido reaberto com a morte de quatro embaixadores romanos pelo tirano de Veios, Lars Tolúmnio. Esta guerra foi marcada pelo combate individual entre Lars Tolúmnio e Cornélio Cosso (tribuno ou cônsul de Roma, conforme polêmica que ainda perdurava à época de Augusto; cf. Liv. 4.20.5-11). O vencedor, romano, foi celebrado com honras antes dadas apenas a Rômulo. Os Romanos, na ofensiva então, cercam e tomam Fidenas. Depois de dominada, a cidade se rebela contra os Romanos que a destruíram, encerrando esta etapa do conflito com uma paz com Veios que selou seu controle sobre a área estratégica em disputa.

A terceira guerra veia corresponde ao cerco e conquista de Veios pelos Romanos. Trata-se de uma vitória importante, que levou à ocupação do extenso território da cidade rival, com a anexação de $562 \mathrm{~km}^{2}$ como

15 Não será o mesmo dizer que é uma guerra entre Latinos e Etruscos. Do lado etrusco, não houve uma unidade em favor de Veios uma vez que se os Tarquínios parecem ter apoiado essa cidade, Clúsio se manteve neutra nos conflitos e Cere esteve ao lado dos Romanos. Cf. Cornell 1995313.

16 Como as terras dos Fábios se localizavam na fronteira do território etrusco, eles movem por sua conta a ocupação de uma área estratégica no rio Cremera, em 497. Este rio é um afluente do Tibre que leva à cidade de Veios. Dois anos depois, um contra-ataque no qual 306 Fábios foram mortos selou a perda da posição romana. Houve apenas um sobrevivente que pôde perpetuar a gens. (Cf. Liv. 2.48.8-50.11) Para se ter ideia da importância desta derrota, vale destacar que entre os anos 485 e 479 um dos cônsules sempre foi um Fábio. Depois da derrota, os fasti consulares só voltam a registrar o nome de um Fabius em 467. Não por acaso, trata-se de Quinto Fábio Vibulano, o sobrevivente de Cremera. Cf. Cornell 1989297.

17 A região teria estado sob controle romano desde os tempos de Rômulo, que a conquistou e estabeleceu ali uma colônia. 
ager publicus, incorporação de novos contingentes populacionais, com a criação de quatro novas tribos (Liv. 6.5.8), e a uma relativa estabilização da fronteira ao norte da cidade. Os relatos que nos restam dos episódios desta guerra estão marcados sempre por uma forte dose de misticismo e acontecimentos de caráter religioso. A proximidade com a épica, dada até mesmo pela informação de que o cerco de Veios teria se estendido por dez $\operatorname{anos}^{18}$ (Liv. 5.22.8), perpassa todos os relatos e provavelmente deriva das fontes usadas pelos historiadores antigos - quer sejam elas os relatos etruscos quer sejam a própria poesia épica produzida pelos contemporâneos. Tito Lívio a saúda como a maior vitória romana até então (3.23.3).

As conquistas de Veios e, na sequência, de áreas que operavam como satélites dela (como Capena - 395 - e Faléria - 39419) podem ser vistas como um conjunto de ações militares romanas no final do século $\mathrm{V}$ com vistas a ampliar e consolidar seus domínios. Tito Lívio registra a de Bola (415 - Liv. 4.49.3-11), Ferentino (413 - Liv. 4.51.7), Carvento (410 - Liv. 4.53.3-10) e Artena (404 - Liv. 4.51.6-11), todas ao sul, sendo que, no litoral, se destaca a tomada de Tarracina (406 - Liv. 4.59.3-10).

Esta mudança de postura se relaciona com reformas no exército, especialmente com a instituição do pagamento das tropas através do stipendium (406) e o estabelecimento de um tributum sobre a propriedade com vistas a financiar as tropas e a imposição dos pagamentos de indenizações por comunidades derrotadas (a começar por Faléria, em 394; cf. Liv.. 5.27.15). Tais mudanças guardam relações com este cenário externo, mas também com mudanças internas, especialmente a reforma do sistema centuriato, com a introdução de classes censitárias no lugar das antigas classes "servianas".

\footnotetext{
18 Não, por acaso, como no cerco de Troia.

${ }^{19}$ Ambas cidades situadas mais ao norte, seguindo o curso do rio Tibre. Estas cidades, tradicionais aliadas de Veios, tinham populações de origem latina, provavelmente. Trata-se de mais um indicativo de que as alianças não se orientavam segundo critérios étnicos e a guerra entre Roma e Veios não pode ser tratada como uma guerra entre Latinos e Etruscos, mesmo porque as demais cidades etruscas em momento algum vieram em socorro de Veios. Este fato procura ser explicado por Tito Lívio pela acusação de impiedade que pesava sobre governantes da cidade.
} 


\section{A invasão gaulesa}

Como temos visto, Roma foi consolidando pouco a pouco a posição de principal cidade em sua região e se sobrepondo de forma bastante segura frente àquelas populações que ameaçavam sua autonomia nos princípios da República. Considerando este cenário, a invasão e destruição de Roma pelos Gauleses no início do século IV foi como uma tempestade caindo de um céu claro ${ }^{20}$.

Em 390 (ou em 387 ou 386, a data não é segura ${ }^{21}$ ), um grupo de Gauleses do vale do rio Pó atravessou os Apeninos em direção à Etrúria setentrional. Avançando para o sul, pararam em Clúsio, no vale do rio Clânis (actual Chiana) e de lá partiram para o vale do rio Tibre, em direção a Roma. Um exército foi rapidamente reunido para confrontar os invasores gauleses. Os Romanos foram derrotados no rio Ália e dispersaram para Veios, deixando o caminho para Roma aberto para os invasores. Os Gauleses entraram na cidade, fizeram um saque e a destruíram em sua maior parte. Foi preservado apenas o Capitólio, defendido por uma pequena guarnição. Os Gauleses deixaram então a cidade, quer por terem recebido um resgate para ir embora, quer por terem sido expulsos por uma tropa formada pelos remanescentes derrotados no rio Ália e reorganizados por Camilo.

A movimentação gaulesa foi um evento de grande importância, sendo noticiada por fontes gregas do século IV ${ }^{22}$. É a primeira atividade relativa a Roma que é percebida por observadores gregos, até onde sabemos. Trata-se de um grande movimento populacional, e não simplesmente um desastre noticiado apenas pelos Romanos. Sendo assim, é importante investigar de onde veio esta invasão que parece inexplicável se temos

\footnotetext{
${ }^{20}$ Roma, como vimos, construía até esse momento um processo de expansão e afirmação na região que parecia ser seguro. Um dado apresentado por Cornell (1995 320) ajuda a dar contornos mais claros a esse crescimento do poderio romano até o ataque gaulês: "É possível calcular que o ager Romanus cresceu mais de $75 \%$ desde o início do século V a.C., de cerca de $900 \mathrm{~km}^{2}$ em 495 para c. $1582 \mathrm{~km}^{2}$ em 396".

21 Segundo Políbio, a invasão se deu no mesmo ano da paz de Antálcidas e do cerco de Régio por Dionísio I de Siracusa. Se Políbio tem razão, a cronologia mais seguida para o evento, a "Varroniana", teria adiantado a data do saque de Roma em três ou quatro anos.

22 Arist., fr. 568 Rose = Plu. Cam. 22.3-4; Theopomp.Hist., FGrH 115 = Plin. Nat. 3.57.
} 
nossos olhos presos ao Lácio. Tito Lívio descreve a movimentações de povos gauleses, ao norte, como um deslocamento que se consolidou no início do século IV com a ocupação de uma faixa do Adriático que seria chamada pelos Romanos justamente de Ager gallicus. Foi esta população gaulesa que se fixou no Adriático, os Sénones, que teria atravessado os Apeninos e tomado Roma, segundo Tito Lívio (5.34.1-35.3). A invasão dos Gauleses teria por alvo os campos cultivados da Itália e, especialmente, seus vinhedos. A estabilidade trouxe alguma prosperidade e esta prosperidade atraía a cobiça de populações que estavam menos organizadas ao norte. Ainda que o relato de Tito Lívio não seja bastante preciso e possa ser questionado, ele nos parece suficiente, especialmente se consideramos que os registros arqueológicos não dão informações que possam claramente confrontar a narrativa liviana no que se refere à lenta penetração dos Gauleses na península Itálica e a fixação de parte deles no Adriático 23 .

As razões que levaram os Gauleses a avançar através da península Itálica são difíceis de clarificar, contudo. Se eles procuravam terras, parecem ter penetrado bastante além do que seria necessário. Parece, pelo relato de Tito Lívio, que esta era a demanda inicial deles, colocada aos Clúsios. Mas não há explicação possível para o fato de, depois de eles terem derrotados estes, terem avançado para Roma e depois seguido em combate mais para o sul. Uma possibilidade para explicar esta trajetória é a pista dada por outras fontes de que os Gauleses atuariam como mercenários de Siracusa (Justin. 20.5.1-6; D.H. 14.117.7; Str. 5.2.3), buscando enfraquecer por terra a posição de Cere (Caere, actual Cervetere), cidade etrusca no Tirreno. O fato de Estrabão dizer que foram os Ceretanos que recuperaram o tesouro saqueado pelos Gauleses aos Romanos, e de Dionísio de Halicarnasso informar que os Gauleses foram derrotados pelos Etruscos de Cere na planície Trausiana (que é mencionada por Dionísio, mas que infelizmente não sabemos onde ficava) quando retornavam para sua área de origem, reforça esta hipótese e nos leva a ler de outra maneira a versão de Tito Lívio de

23 Para uma discussão sobre estes problemas e bibliografia, ver Cornell 1989303. 
que Camilo teria reunido os remanescentes militares romanos e derrotado os Gauleses. É certo que havia um conflito entre Siracusanos e Ceretanos e talvez a invasão gaulesa se explique mais por este contexto do que pela busca de novas terras. Além disso, a vitória salvadora de Camilo, como relatada por Tito Lívio, não teria tido os contornos dados por esta fonte, mas se combinaria com uma reação de outras cidades invadidas, especialmente dos Etruscos ao sul, que teriam feito frente a estes mercenários gauleses aliados aos Siracusanos.

Podemos pensar, com Cornell (1989 307), que se pode tomar "a lenda de Camilo para substituir o papel histórico de Cere”. Para concluir, então, cremos que é possível afirmar que a movimentação dos Gauleses não teve como motivação principal a busca de novas terras, mas ganhos mais imediatos - atuando como mercenários de Siracusa e promovendo saques. A derrota de Roma não implicou em perdas humanas tão expressivas - sendo que na prática houve no máximo dois enfrentamentos entre Romanos e Gauleses (a derrota no rio Ália e o combate para liberar Roma). Mesmo considerando que a derrota ficou marcada na memória romana como uma grande humilhação, como atesta Tito Lívio (5.48.8-9)²4, não há provas de destruição expressiva de edificações na cidade - não há remanescentes arqueológicos indicando incêndio ou qualquer outra destruição expressiva. Ademais, se o objetivo gaulês era mesmo como indicamos o saque, não teria razão de ser tal aniquilação. Aos ocupantes só interessava aquilo que pudesse ser levado, como o ouro pago para liberar a cidade. O melhor indício de que não houve uma destruição extensiva ou grandes perdas humanas é o fato de que a recuperação de Roma foi extremamente rápida e muito efetiva ${ }^{25}$.

${ }^{24}$ Especialmente quando Tito Lívio afirma que o senado deliberou pagar "1000 pesos [c. $327 \mathrm{~kg}$ ] de ouro como o preço da pátria que logo iria governar o mundo. Isso foi uma imensa desonra, mas outro insulto foi acrescido: os pesos trazidos pelos Gauleses eram mais pesados do que deveriam ser e, quando o tribuno protestou, o insolente gaulês [Breno, que os comandava] jogou sua espada junto aos pesos dizendo as palavras que os Romanos não suportariam ouvir: 'Ai dos vencidos!'.”

25 Michael Crawford (1992 32) avalia da seguinte maneira os efeitos mais imediatos do saque de Roma: "Há evidência irrefutável para a fundamental irrelevância do saque gaulês para a expansão romana e seu efeito desprezível sobre o poderio romano". 


\section{A recuperação de Roma}

Políbio afirma que depois do saque de Roma liderado pelo gaulês Breno, passaram-se trinta anos para que eles retornassem ao Lácio e que neste período Roma teria retomado a hegemonia na região (11.18.5-6). Cremos que é possível afirmar que no momento em que Roma era derrotada, suas alianças tinham se perdido, e Latinos e Hérnicos não estiveram ao lado dos Romanos. O foedus Cassianum era letra morta então. Permitindo perceber claramente que os danos não foram tão grandes, logo depois da humilhante derrota para os Gauleses, os Romanos passam a obter seguidas vitórias uma vez mais, chegando à metade do século IV em uma posição mais forte do que aquela que tinham quando Breno levou o ouro romano.

Após resistir a ataques de Etruscos do norte em 389 e 386, os Romanos atacam interesses Etruscos no sul, no território de Tarquínios e ocupam novas áreas (Liv. 6.4.8-10). Para consolidar esta fronteira mais ao sul, estabelecem novas colônias. Para a construção desta posição importante foi fundamental a aliança com os Ceretanos ${ }^{26}$. Esta aliança parece ter acabado apenas com uma guerra entre as duas cidades que foi concluída com uma aliança feita em 353 na qual Cere é tratada de forma diferenciada por conta dos inúmeros serviços prestados a Roma antes (especialmente contra os Gauleses e Tarquínios), como nos informa Tito Lívio (7.20). Logo após sofrerem o saque, os Romanos também atacam os Équos, anexando a planície Pontina (de Pomptinum) e formando colônias ao longo da região (Satricum, em 385, e Setia, em 382). Isto pareceu neutralizar uma vez mais estes adversários que voltam a ser mencionados novamente nos registros romanos apenas em 304, em razão de uma revolta mal sucedida.

${ }^{26}$ Indicando mais uma vez que é exagerada a visão que coloca Roma em uma posição destacada desde sempre, importa notar que o acordo entre Roma e Cere (Caere) é marcado por uma certa simetria. Envolvia o que Tito Lívio (5.50.3) chamou de hospitium publicum, ou seja, o reconhecimento de cidadania entre as duas cidades (e não a absorção de Cere na cidadania romana, como erroneamente se poderia entender assumindo que Roma teria como impor uma superioridade inconteste a Cere, então). Importante destacar que o mesmo tipo de acordo havia sido feito antes com Massília, no contexto da guerra contra os Gauleses. Não parece ser, portanto, uma prática criada pelos Romanos, mas algo que já era corrente. Cf. Cornell 1995321. 
A retomada da estabilidade das alianças com Latinos e Hérnicos, ou dito de outro modo, a reabilitação do foedus Cassianum, aparece de forma algo confusa nas fontes, uma vez que ele parece não ter sido contestado. Tito Lívio (6.10.6) faz uma afirmação interessante: "No mesmo ano foi pedida reparação e explicação porque ao longo de anos não deram apoio militar como previa o acordo" 27 . Deste modo, ao que parece, a instabilidade afastou estes aliados e a retomada do controle da região os trouxe de volta, sem maiores conflitos entre Romanos, Latinos e Hérnicos.

Ainda assim, os conflitos com muitas cidades continuavam. Algumas cidades aliadas de Roma tenderam a se voltar para os Volscos na medida em que Roma tem uma política cada vez mais claramente expansionista, como ilustram os casos de Tíbur, Preneste e, ainda mais claramente, de Túsculo²8.

Depois de um período de relativa calma entre 376 e 363, que é marcado no relato de Tito Lívio por uma atenção quase exclusiva aos assuntos internos (com a exceção dos conflitos envolvendo a região Pontina, com sucessivas perdas e reconquistas da área), Roma retoma um ritmo ainda mais intenso na sua expansão: registra-se o impressionante número de nove triunfos entre os anos 361 e 354 contra apenas quatro após aquele celebrando a liberação da cidade de Roma em 390. A despeito das imprecisões e repetições da tradição analística, parece claro, em termos globais, que os Romanos, por meio dessas guerras, foram não apenas reconstruindo os acordos com os diversos estados na Itália central, mas também estabelecendo condições ainda mais assimétricas como resultado de suas vitórias contra Latinos, Hérnicos e Volscos. Além disso, consegui-

${ }^{27}$ Eodem anno ab Latinis Hernicisque res repetitae quaesitumque cur per eos annos militem ex instituto non dedissent. O motivo da reclamação romana era que Latinos e Hérnicos haviam lutado com Volscos. Segundo Lívio, ambos explicaram que faltas de uns jovens não deveriam ser imputadas a todos e que eles que foram para os Volscos não haviam voltado e que não vinham fornecendo soldados por temor destes mesmos Volscos que, como peste, os mantinham em guerras. O senado romano avaliou as explicações como suficientes e não lhes fez guerra (6.10.7-9).

${ }^{28}$ No caso de Túsculo, a cidade se rendeu antes de haver um ataque. Os Tusculanos foram então admitidos à cidadania romana (incluídas as mesmas obrigações como o pagamento de tributos e serviço nas legiões), passando a fortalecer o imperium romano (Liv. 6.25.6). É mais um exemplo (compare-se com a menção que fizemos anteriormente a Cere) de que a posição elevada de Roma se produziu com base em um quadro de múltiplas alianças de diferente matiz, coordenando um número crescente de aristocracias com os mais variados status. 
ram neutralizar a ameaça gaulesa. Ainda que não houvesse um acordo de paz (o qual só é noticiado em 331 por Plb. 2.18.9), as frequentes incursões gaulesas (em 367, 361, 360, 358 e 357, segundo Tito Lívio) também deixaram de ocorrer. O olhar de Roma se espraiava agora para novos horizontes, como os acordos entre Roma e os Samnitas (354) e entre Roma e Cartago (348) deixam claro. Em 338, ao fim da guerra entre Romanos e Latinos, a Liga Latina deixa de existir uma vez que praticamente todos os homens livres são incorporados à cidadania romana (com as obrigações tributárias e de serviços militares correspondentes, mesmo que a administração local das cidades continuasse existindo e cada uma delas tenha sido tratada de forma diferenciada e individualizada, como relata Tito Lívio 8.14.1-12). Poucas cidades não foram incluídas nessa política, como é o caso de Tíbur e Preneste que seguiram independentes, mas não podiam conduzir uma política externa própria para afrontar os Romanos que os cercavam por todos os lados agora. Outras cidades itálicas, para além dos aliados latinos, são beneficiadas com a cidadania romana, mas sem o direito a voto (são as civitates sine suffragio), como é o caso de Cápua e suas aliadas, na Campânia (Oakley 200425 ).

Desse modo, Roma tinha desde meados do século IV uma importância não desprezível para os conflitos no Mediterrâneo Ocidental. Uma nova etapa se abria com as grandes guerras samnitas que viriam com a consolidação deste novo lugar que Roma ocupava no centro da Itália.

\section{Conclusão}

Como vimos, Roma constituiu através deste processo de expansão um verdadeiro "império de cidades" (Guarinello 2008). Como se tratava de um Estado em expansão, um ponto de tensão constante será qual a contribuição que será dada por cada uma dessas comunidades políticas para as guerras movidas por Roma e quanto cada cidade, e até mesmo cada setor da aristocracia e ainda cada aristocrata, se beneficiaria com essas guerras. As guerras traziam butins, mais terra, mais poder, mais glória e, eventualmente, mais aristocratas para o interior do Estado Romano. 
Mediante acordos diversos e independentes entre si, Roma afirmou sua hegemonia e poderio sobre cada um dos setores aliados que se mantinham em separado por este processo, não constituindo uma aliança unificada ou uma federação. Podemos explicar esta hegemonia de Roma, então, pelo fato de Roma ser o centro de uma rede de alianças que não poderia existir sem a sua intermediação. As cidades desta aliança não estavam unidas entre si, mas estavam ligadas a Roma. Estar no centro de uma rede de alianças será um importante sinônimo de poder para a história de Roma tanto no que se refere à constituição do Império quanto da aristocracia que governou este Império. Cremos que esta dinâmica é como uma importante marca de nascença do Império Romano e vai se manter como uma categoria explicativa mesmo quando o poder se centralizar mais e mais em Roma, sob os imperadores.

A nosso ver, mesmo Roma sendo mais tarde o centro do Império, importa prestar atenção ao que se passa fora daquela cidade. Ainda que a elite romana governe o mundo, é decisivo estar atento a como se liga às demais elites e como se dá a sua renovação ao longo do tempo. Em outras palavras, é importante avaliar o poder eventualmente centralizado por Roma como o resultado de jogos de força e de interesses que sempre está se renovando em condições que nunca são exatamente as mesmas.

\section{Tábua cronológica}

499 ou 496 a.C. - Batalha do Lago Regilo, com vitória romana sobre Latinos.

493 a.C. - Foedus Cassianum.

431 a.C. - Batalha do monte Algido, empreendida pelos Romanos contra Équos e Volscos. 405-396 a.C. - Cerco e conquista de Veios pelos Romanos.

390 a.C. - Invasão de Roma pelos Gauleses.

\section{Bibliografia}

Eckstein, A. M. (2006), Mediterranean anarchy, interstate war, and the rise of Rome, Berkeley, University of California Press.

Forsythe, G. (2005), A critical history of early Rome: from prebistory to the first Punic War, Berkeley, University of California Press. 
Bringmann, K. (2007), A bistory of the Roman Republic, Cambridge, Polity Press.

Crawford, M. (1988), "Early Rome and Italy", in J. Boardman et alii, eds., The Oxford history of the Classical World. The Roman World, Oxford, Oxford University Press 9-38.

Crawford, M. (21992), The Roman republic, London, Fontana Press.

Guarinello, N. L. (2008), "Império e Imperialismo: realidades antigas e conceitos contemporâneos", in A. Campos et alii, eds., Os Impérios e suas matrizes politicas e culturais, Vitória, Flor e Cultura 10-18.

Southern, P. (2011), Ancient Rome. The Republic - 753BC-30BC. Stroud, Amberley Publishing.

Oakley, S. P. (2004), "The early Republic”, in H. I. Flower, ed., The Cambridge companion to the Roman Republic, Cambridge, Cambridge University Press 15-30.

Cornell, T. J. (1989), "Rome and Latium to 390 B.C.", in F. W. Walbank - A. E. Astin - M. W. Frederiksen, eds., The Cambridge Ancient History, vol. 7.2., Cambridge, Cambridge University Press 243-308.

Cornell, T. J. (1995), The beginnings of Rome. Italy and Rome from the Bronze Age to the Punic Wars (c. 1000-264 BC), London, Routledge.

Harris, W. V. (1979), War and Imperialism in Republican Rome, Oxford, Oxford University Press. 